\title{
Mechanisms of Antitumor Activity of Aqueous Extracts from Chinese Herbs: Their Immunopharmacological Properties
}

\author{
Hiroshi MORI, Qiang XU, Osami SAKAMOTO, Yûki UESUGI, \\ Akihide KODA and Itsuo NISHIOKA ${ }^{1}$ \\ Department of Pharmacology, Gifu Pharmaceutical University, Gifu 502, Japan \\ 1 Department of Pharmacognosy, Faculty of Pharmaceutical Sciences, \\ Kyushu University, Fukuoka 812, Japan \\ Accepted December 9, 1988
}

\begin{abstract}
Previously we reported the antitumor activity of 4 kinds of Chinese herbs: $A$. capillaris, $S$. doederleinii, A. macrocephala and $S$. subprostrata. Evidence has been also presented that $A$. capillaris shows the activity mainly through a direct tumoricidal action and the others display the activity through the enhancement of tumor-immune response. The present results are as follows: A. capillaris did not affect Meth A tumor-neutralizing activity (Winn's assay) in spleen cells of BALB/C mice bearing the primary tumor. The other herbs enhanced the activity on days 10 and 15 and prevented the decay of the activity on day 20 after the Meth A tumor transplantation. However, none of them enhanced the local graft versus host reaction $(\mathrm{GVHR})$ induced in $\mathrm{CBF}_{1}$ mice by spleen cells of $\mathrm{BALB} / \mathrm{c}$ mice. A. capillaris hardly affected the humoral antibody formation against sheep red blood cells in mice. On the contrary, the other 3 herbs enhanced the formation. Blast transformation of murine lymphocytes with PHA-P or LPS was suppressed by $10^{-5}$ to $10^{-4} \mathrm{~g} / \mathrm{ml}$ of $A$. capillaris. A. macrocephala enhanced the response by LPS. It should be noted that $A$. capillaris showed no immunosuppressive action in spite of having a direct tumoricidal action in vitro. Further investigations will be required on the latter 3 herbs to clarify the relationship between their humoral immunitystimulating activity and their tumor immunity-enhancing activity.
\end{abstract}

It has been well-documented that BALB/C mice immunologically respond to Meth $A$ tumor. Namely, these mice can resist the growth of a subcutaneously implanted Meth A tumor if they are treated with immunostimulating agents such as LPS $(1,2)$ and Corynebacterium parvum (3). In the previous paper (4) using the syngeneic system of Meth A tumor and BALB/c mice, we demonstrated the antitumor activity of 4 kinds of Chinese herbs: A. capillaris, S. doederleinii, A. macrocephala and S. subprostrata. A. capillaris significantly inhibited the growth of Meth $A$ tumor even in BALB/C-nu/nu mice, while the others did not. It was also shown that $A$. capillaris had cytotoxic activity against Meth A tumor and L-929 cells in an in vitro study. Further investigation (5) regarding the antitumor mechanisms of these herbs in- dicated that all of them enhanced the Meth A tumor-induced delayed type hypersensitivity reaction (Meth A-DTH), although they did not affect the picryl chloride-induced delayed type hypersensitivity reaction (PC-DTH). These observations suggest that $A$. capillaris shows the antitumor activity by a mechanism mainly based on a direct tumoricidal action. although this herb includes some components that can enhance Meth A-DTH. The other 3 herbs display the activity through the enhancement of $T$ cell-mediated immunity. particularly tumor specific delayed type hypersensitivity.

In the present paper, to reconfirm the effect of these Chinese herbs on tumor immunity, we intended to examine whether these herbs enhance the tumor-neutralizing activity in spleen cells of mice bearing Meth 
A tumor. In addition, we studied the effects of these herbs on some immune responses other than the tumor-immune response to clarify their immunopharmacological properties.

\section{Materials and Methods}

1. Drugs: Chinese herbs employed in this study were as follows: Artemisia capillaris THUNB., Selaginella doederleinii HIERON., Atractylodes macrocephala KOIDZ. and Sophora subprostrata CHUN et T. CHEN. Aqueous extracts from these Chinese herbs were made by the ordinary methods, which were described previously $(4,5)$. The yields of the extracts were $13.4 \%$ from $A$. capillaris, $7.4 \%$ from $S$. doederleinii, $38.1 \%$ from $A$. macrocephala and $17.2 \%$ from S. subprostrata. The following materials were also employed: benzylpenicillin potassium-treated and lyophilized cells of the Streptococcus pyogenes Su strain (A group, type 3) (OK-432, Chugai Pharmaceutical Co., Ltd., Tokyo, Japan), prednisolone (Takeda Chemical Industries, Ltd., Osaka, Japan) and cyclophosphamide (CY, Nakalai Tesque, Inc., Kyoto, Japan). The dose of OK-432 was expressed as units of Klinische Einheit (KE), where one $\mathrm{KE}$ contains $0.1 \mathrm{mg}$ of dried whole cells of $S$. pyogenes. They were dissolved or suspended in distilled water for oral administration and in saline for parenteral dosing. For the in vitro assay, the aqueous extracts of Chinese herbs were dissolved in the culture medium described below and sterilized with a $0.45 \mu \mathrm{m}$ cellulose acetate membrane.

2. Animals: $B A L B / C,(B A L B / C \times C 57 B L / 6)$ $F_{1}\left(C B F_{1}\right)$ and ddY strains of female mice were purchased from Shizuoka Experimental Animal Center (Hamamatsu, Japan) and maintained in laminar-air-flow cages at $22 \pm 1{ }^{\circ} \mathrm{C}$ and $60 \%$ humidity. They were allowed free access to pellet food and water and used for the experiments when they were 8 to 12 weeks of age.

3. Tumor cells: Meth A tumor cells were obtained from Aichi Cancer Center (Nagoya, Japan) and maintained by weekly passage in the peritoneal cavity of BALB/C mice in our laboratory.

4. Preparation of spleen cell suspension: Spleens were aseptically taken from mice and gently crushed and separated into single cells by squeezing in Hanks' solution containing $5 \mathrm{U} / \mathrm{ml}$ heparin. The cells obtained were passed through a fine stainless steel sieve (200 mesh) and washed twice with Hanks' solution. followed by resuspension in an appropriate medium.

5. Tumor-neutralizing activity of spleen cells: One million Meth A cells were inoculated s.c. into the flanks of BALB/C mice. They were killed 10, 15 and 20 days after the inoculation to provide spleen cells for examining the neutralizing activity against Meth A cells by Winn's assay. Namely, $10^{7}$ spleen cells from the mice were mixed with $10^{5}$ Meth A cells. The mixture from one mouse was inoculated s.c. into the flanks of two normal BALB/C mice. Tumor size (the mean of 2 mice) was measured 15 days after the inoculation using vernier calipers in terms of 2 diameters at right angles. Tumor size was expressed as volume $(4 / 3 \pi \times$ (long diameter/2) $\left.\times(\text { short diameter/2 })^{2} \mathrm{~cm}^{3}\right)$, and the neutralizing activity of spleen cells was represented as the percent tumor size to that of the control mice which had been inoculated with the mixture of normal spleen cells and Meth A cells.

6 . Local graft versus host reaction (local GvHR): Ten million spleen cells from CBF, and $B A L B / C$ mice were inoculated in a volume of $0.1 \mathrm{ml}$ suspension, s.C., into the left and right footpads of $\mathrm{CBF}_{1}$ mice, respectively. The severity of GVHR was evaluated by the weight difference between the right and left popliteal lymph node of the recipient 8 days after the inoculation.

7. Plaque forming cell (PFC) production in spleen and serum antibody formation: Sheep red blood cells (SRBC) were used as an antigen. SRBC stored in Alsever's solution was washed and resuspended into an appropriate solution [sterilized saline for immunization, Eagle's MEM for PFC assay and phosphate-buffered saline (PBS, $8 \mathrm{~g} \mathrm{NaCl}$, $1.43 \mathrm{~g} \mathrm{Na}_{2} \mathrm{HPO}_{4} \cdot 2 \mathrm{H}_{2} \mathrm{O}$ and $\mathrm{KH}_{2} \mathrm{PO}_{4}$ in a liter of distilled water, $\mathrm{pH}$ 7.4) for serum antibody titration]. ddY mice were immunized with the i.v. injection of $2 \times 10^{8}$ SRBC. They were killed 5 and 10 days after the immunization, and spleen weight, number of PFC in the spleen and serum antibody titer were 
measured. Direct PFC and indirect PFC in the spleen were detected according to Cunningham and Szenberg (6). Rabbit antimouse IgG (FC specific, The Medical and Biological Laboratories, Nagoya, Japan) was used at a final 200-fold dilution for developing indirect PFC. Number of IgG-PFC was calculated as the difference between the numbers of direct and indirect PFCs. The anti-SRBC antibody titer in the serum was measured by enzyme-linked immunosorbent assay (ELISA) as described previously (7). Briefly, SRBC was directly fixed to the bottom of an Aminoplate well (96-well, flat bottom, Sumitomo Bake!ite Co., Osaka, Japan) which had been positively charged. Serum samples were diluted with PBS and added to the well. After $2-\mathrm{hr}$ incubation at $37^{\circ} \mathrm{C}, \mathrm{SRBC}$ on the bottom was washed with PBS, added with a 500 -fold diluted 2 nd antibody of alkaline phosphatase-conjugated affinity purified goat anti-mouse IgM or IgG preparation (Cappel, PA), and incubated 1 hour at $37^{\circ} \mathrm{C}$. After washing, the alkaline phosphatase activity in a well was measured by the Kind and King method (8).

8. Mitogen-induced blast transformation of spleen cells: Spleen cells from BALB/c mice were suspended in the culture medium (RPMI-1640 medium containing 10\% heat inactivated fetal calf serum (Gibco, NY), 10 unit $/ \mathrm{ml}$ penicillin $\mathrm{G}, 100 \mu \mathrm{g} / \mathrm{ml}$ streptomycin and $25 \mathrm{mM} \mathrm{N}$-2-hydroxyethylpiperazine- $\mathrm{N}^{\prime}$ 2-ethanesulfate (HEPES)). Five hundred thousand cells in $0.2 \mathrm{ml}$ volume in a wel! of a flat-bottomed, 96-well culture plate were incubated at $37^{\circ} \mathrm{C}$ for 96 hours under $5 \% \mathrm{CO}_{2}$ in the presence or absence of $20 \mu \mathrm{g} / \mathrm{ml}$ of phytohemagglutinin-P (PHA-P, Difco, MI) and $50 \mu \mathrm{g}$ of lipopolysaccharide (LPS. Escherichia coli 055: B5, Difco, MI). After the incubation, the amount of DNA per well was measured fluorometrically, and the stimulation index (SI) was calculated as follows: $S I=(D N A$ amount of stimulated cells)/(DNA amount of non-stimulated cells). The total DNA amount in cultured cells was measured as described previously (4). Briefly, after removing erythrocytes from the cultured cells in a well with $0.75 \% \mathrm{NH}_{4} \mathrm{Cl}$ solution and washing twice with saline, the residual cells were lysed with $0.2 \mathrm{ml}$ of $0.1 \%$ sodium dodecyl sulfate (SDS) solution. Then, the cell lysate was transferred into a glass tube using $1.8 \mathrm{ml}$ of the SDS solution and mixed with $2 \mathrm{ml}$ of $6 \mu \mathrm{g} / \mathrm{ml}$ ethidium bromide (Nakalai Tesque, Inc., Kyoto, Japan). Fifteen min later, the fluorescence (Ex. 525 $\mathrm{nm}, \mathrm{Em} .600 \mathrm{~nm}$ ) of the solution was measured. DNA amount was calculated from the fluorescence standard curve prepared with DNA (Type I, Sigma, MO).

9. Statistics: For all data shown in the figures and tables, the values were expressed as the mean \pm S.E.M. Willcoxon's rank sum test (U-test) was employed to analyze the significant difference between 2 groups in data for the tumor-neutralizing activity. Student's or Welch's two tailed $t$-test after the $F$-test was used to analyze the significance of difference for the other data. The value of $\mathrm{P}<0.05$ was considered significant.

\section{Results}

1. Effect of Chinese herbs on tumorneutralizing activity of spleen cells in mice bearing Meth A sarcoma: BALB/c mice were given p.o. the aqueous extracts from Chinese herbs in a dose of $250 \mathrm{mg} / \mathrm{kg}$ for 20 days from 4 days before the tumor inoculation. Then, their spleen cells were subjected to Winn's assay. As shown in Fig. 1, the spleen cells in the control group exhibited approximately $17 \%$ neutralizing activity on days 10 and 15 . and then the activity decreased to $-60 \%$ on day 20. A. capillaris did not affect the activity on any day. $S$. doederleinii significantly prevent the reduction of the activity on day 20. A. macrocephala increased the activity significantly on day 10 , but did not affect it on days 15 and 20. S. subprostrata showed a tendency to increase the activity on days 15 and 20 .

2. Effect of Chinese herbs on local GvHR: The local GvHR was induced in BALB/C mice by inoculating spleen cells of $C B F_{1}$ mice as described under Methods. The recipient mice were given p.o. the aqueous extracts of Chinese herbs in doses of 250 and $500 \mathrm{mg} / \mathrm{kg}$ for 12 days from 4 days before the inoculation. Control mice were administered water as a vehicle. None of the Chinese herbs affected the GvHR except that 


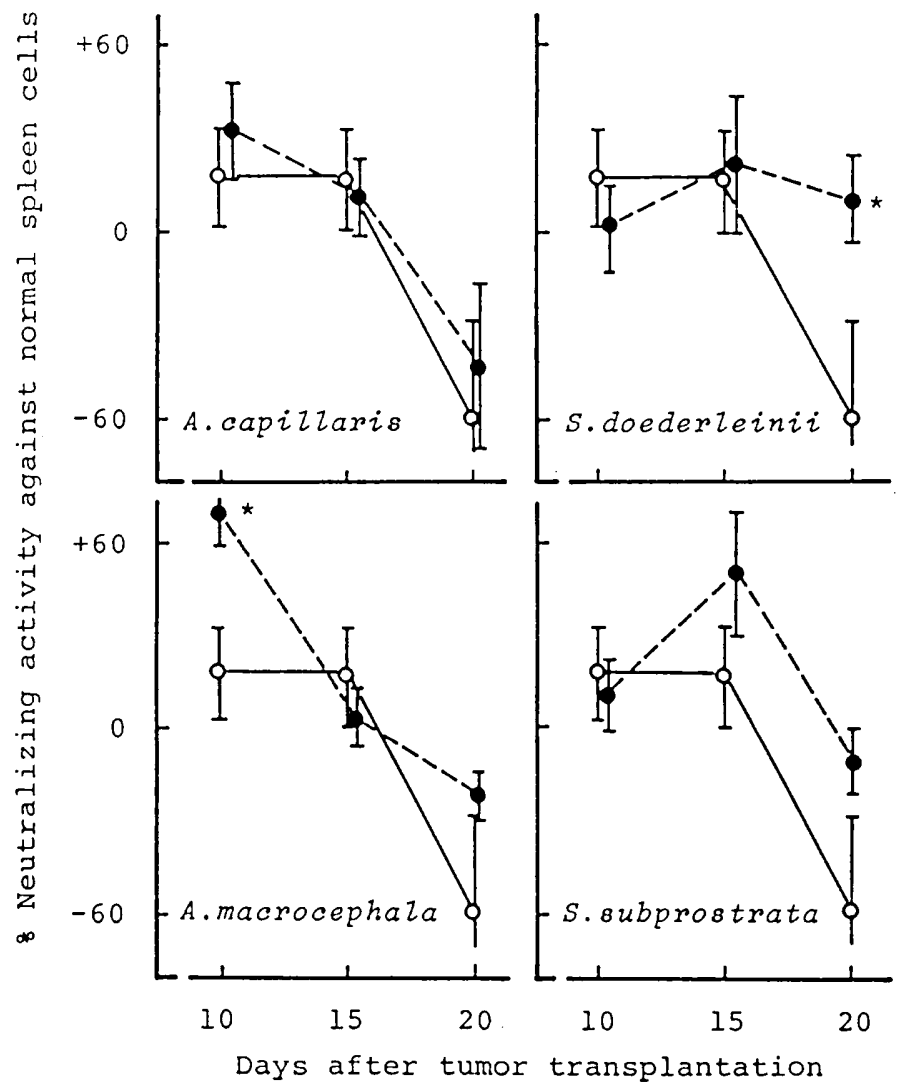

Fig. 1. Effect of Chinese herbs on Meth A tumor-neutralizing activity in spleen cells of female BALB/C mice. Mice, 8 weeks old, were transplanted with $10^{6}$ cells of Meth A tumor, s.c., into their flanks. The aqueous extracts $(250 \mathrm{mg} / \mathrm{kg}$ ) were given p.o. for 20 days from 4 days before the tumor transplantation. Five mice in each group were killed 10.15 and 20 days after the transplantation to provide spleen cells for Winn's assay (Meth A cells : spleen cells=1:100). Each point indicates the mean \pm S.E.M. of 5 animals.

*: Statistically significant difference from the control at $P<0.05$.

$500 \mathrm{mg} / \mathrm{kg}$ of $S$. subprostrata suppressed the response (Fig. 2).

3. Effect of Chinese herbs on PFC production in spleen and serum antibody formation: The aqueous extracts from Chinese herbs were given p.o. for 9 days from 4 days before the SRBC immunization. $C Y$ was given p.o., and OK-432 was given i.p. for 5 days from the immunization. The Chinese herbs hardly affected the spleen weight at any dose on both days 5 and 10 , but $\mathrm{CY}$ showed a tendency to decrease the weight on day 5, and OK-432 significantly increased the weight on day 10 (Table 1). Tables 2 and 3 show the effect of herbs on the number of PFCs per spleen and serum antibody titer. respectively. A. capillaris showed only a tendency to increase $\operatorname{lgM}$ - and $\lg$ G-PFC on day 10 in a dose of $250 \mathrm{mg} / \mathrm{kg}$ as well as $\lg \mathrm{M}$ and $\lg \mathrm{G}$ antibodies in serum. These effects of $A$. capillaris were not remarkable as a whole. S. doederleinii in a dose of 250 $\mathrm{mg} / \mathrm{kg}$ showed a tendency to increase $\mathrm{IgG}$ PFC on both days 5 and 10 as well as $\mathrm{IgG}$ antibody in the serum. Five hundred $\mathrm{mg} / \mathrm{kg}$ of this herb increased IgM- and IgG-PFC markedly on day 10 as well as $\lg$ antibody on day 5 and $\operatorname{lgM}$ - and $\operatorname{lgG}$-antibodies on day 10. A. macrocephala in doses of 250 and $500 \mathrm{mg} / \mathrm{kg}$ increased all parameters of PFC. except for no increase of IgG-PFC on day 5 at the dose of $250 \mathrm{mg} / \mathrm{kg}$, while $\operatorname{lgM}$ and !gG antibodies increased on day 10. $S$. subprostrata at both doses increased IgG- 


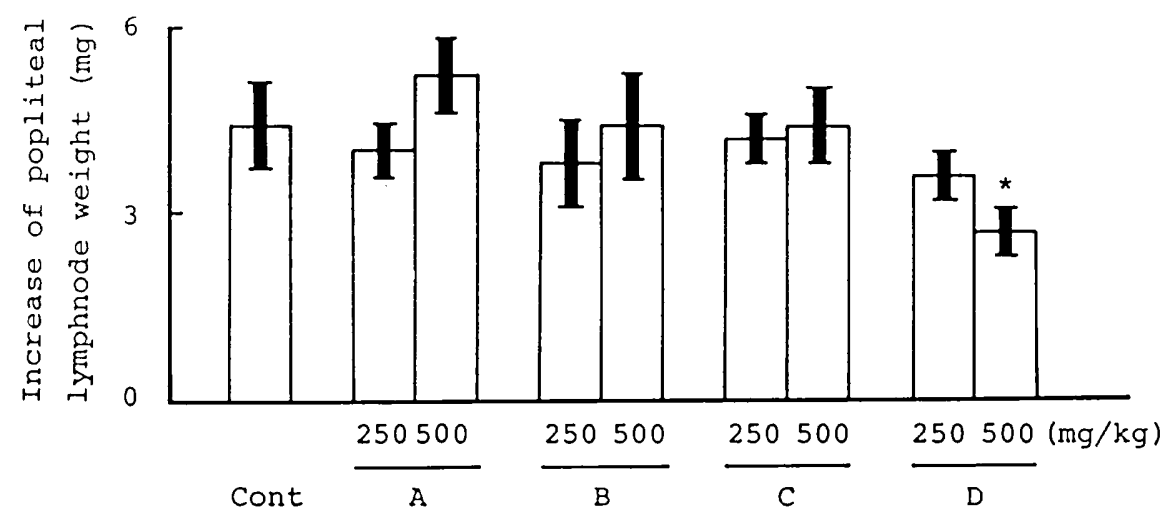

Fig. 2. Effect of A. capillaris (A), S. doederleinii (B), A. macrocephala (C) and S. subprostrata (D) on local GvHR in female $\mathrm{CBF}_{1}$ mice. The million spleen cells from $\mathrm{CBF}_{1}$ and $B A L B / c$ mice were inoculated s.c. into the left and right feet of 8 week-old $C_{B F}$ mice, respectively. Recipient mice were p.o. given the aqueous extracts for 12 days from 4 days before the inoculation. GvHR was evaluated by the weight difference between the right and left popliteal lymph nodes 8 days after the inoculation. Each column represents the mean \pm S.E.M. of 7 to 8 animals. *: Statistically significant difference from the control at $P<0.05$.

Table 1. Effect of Chinese herbs on spleen weight of mice

$\begin{array}{lccc} & \begin{array}{c}\text { Dose } \\ (\mathrm{mg} / \mathrm{kg})\end{array} & \text { Soleen weight }(\mathrm{mg}) \\ \text { Control } & & 135 \pm 7.8 & \text { Day } 10 \\ \text { A. capillaris } & 250 & 135 \pm 11.0 & 117 \pm 5.7 \\ & 500 & 141 \pm 10.0 & 120 \pm 6.9 \\ \text { S. doederleinii } & 250 & 130 \pm 9.4 & 109 \pm 4.1 \\ & 500 & 140 \pm 7.2 & 113 \pm 9.8 \\ \text { A. macrocephala } & 250 & 140 \pm 10.2 & 124 \pm 5.9 \\ & 500 & 135 \pm 12.7 & 113 \pm 3.6 \\ \text { S. subprostrata } & 250 & 141 \pm 5.7 & 119 \pm 9.0 \\ \text { CY } & 500 & 129 \pm 7.4 & 123 \pm 9.7 \\ \text { OK-432 } & 10 & 125 \pm 8.6 & 107 \pm 5.3 \\ \text { mice } & 1 \mathrm{KE} \text { animal } & 150 \pm 7.2 & 105 \pm 9.5\end{array}$

ddY mice were immunized i.v. with $2 \times 10^{8} \mathrm{SRBC}$. The aqueous extracts were given p.o. for 9 days from 4 days before the SRBC immunization. CY was given p.o. and OK-432 was given i.p. for 5 days from the immunization. Each group included 8 mice except $\mathrm{fo}$ : the group of 7 mice given $500 \mathrm{mg} / \mathrm{kg}$ of $A$. macrocephala on day 10 and the group of 7 mice given $500 \mathrm{mg} / \mathrm{kg}$ of $S$. subprostrata on day 10 . Measurements were done 5 and 10 days after the immunization. **: Statistically significant difference from the control at $\mathrm{P}<0.01$.

PFC on day 5 and increased IgM- and IgGPFC on day 10 . In this case, $250 \mathrm{mg} / \mathrm{kg}$ of the herb increased $\lg M$ antibody and 500 $\mathrm{mg} / \mathrm{kg}$ increased $\mathrm{lgG}$ antibody on day 10 . CY suppressed IgM- and IgG-PFCs on day 5 as well as $\lg M$ and $\lg G$ antibodies, but not on day 10. OK-432 increased IgG-PFC on day 5 and $\lg M$ - and $\lg$-PFC on day 10 as well as $\lg G$ antibody on day 10 .

4. Effect of Chinese herbs on mitogeninduced blast transformation of spleen cells: Spleen cells of BALB/c mice were incubated 

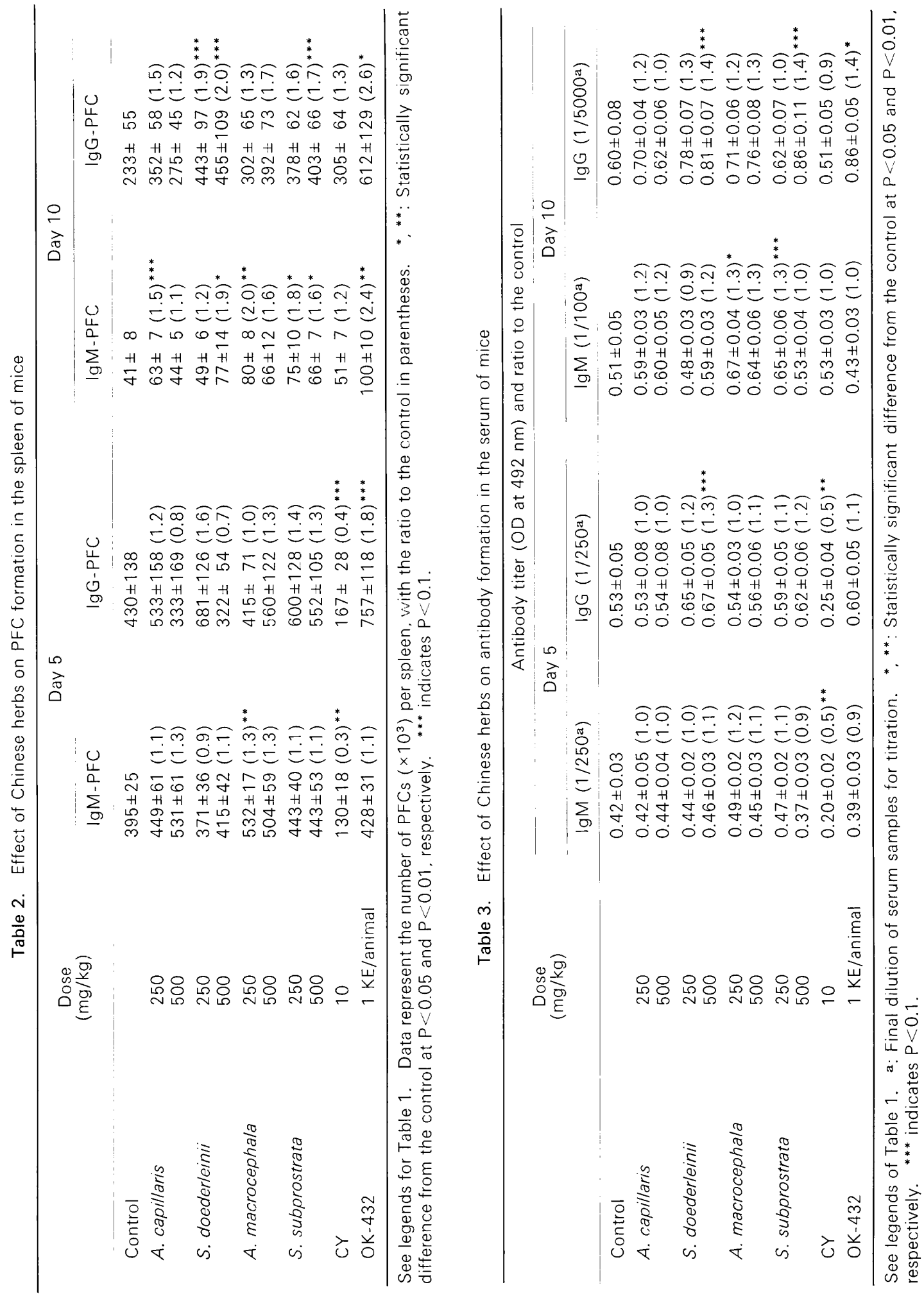


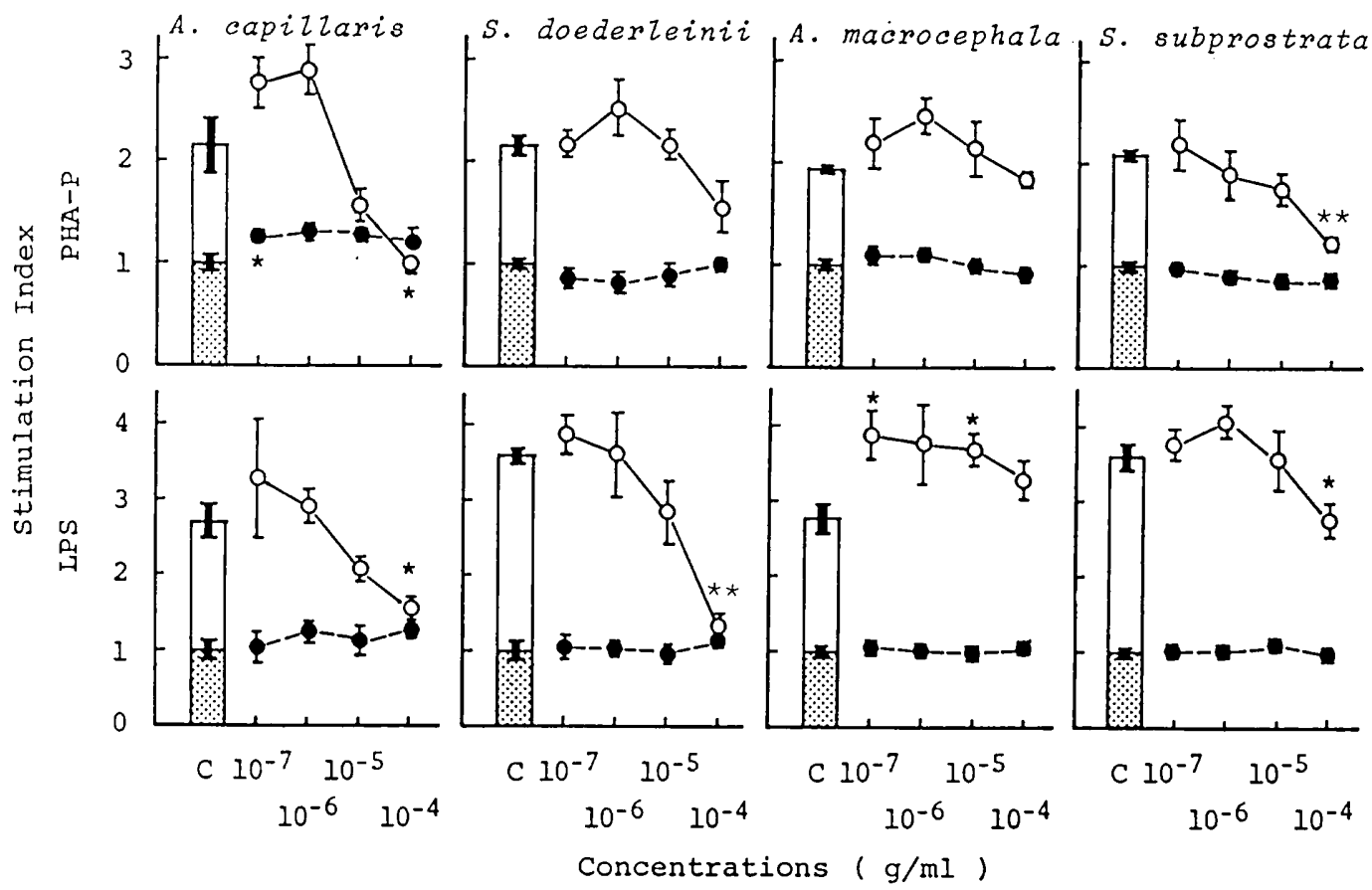

Fig. 3. Effect of A. capillaris, S. doederleinii, A. macrocephala and S. subprostrata on PHA-P or LPS induced blast transformation of spleen cells from BALB/c mice. Spleen cells $\left(5 \times 10^{6} /\right.$ well) were incubated with the aqueous extracts in the presence $\left(\mathrm{O}, \square\right.$ ) or absence $(0 . ; 3)$ of $2 \times 10^{-5} \mathrm{~g} / \mathrm{ml}$ of PHA$P$ or $5 \times 10^{-5} \mathrm{~g} / \mathrm{ml}$ of LPS at $37^{\circ} \mathrm{C}$ for 4 days, respectively. Blastogenesis of lymphocytes was estimated by measuring the amount of DNA with a fluorometric method using ethidium bromide. Each datum indicates the mean \pm S.E.M. of triplicate sets. C: Control. ${ }^{*},{ }^{* *}$ : Statistically significant difference from the control at $P<0.05$ and $P<0.01$, respectively.

with $10^{-7}-10^{-4} \mathrm{~g} / \mathrm{ml}$ of the aqueous extracts from Chinese herbs in the presence or absence of $20 \mu \mathrm{g}$ of PHA-P or $50 \mu \mathrm{g}$ of LPS at $37^{\circ} \mathrm{C}$ for $96 \mathrm{hr}$. Sls of the control were between 1.94 and 2.14 in PHA-P stimulation and between 2.70 and 3.62 in LPS stimulation (Fig. 3). A. capillaris showed a tendency to increase $\mathrm{SI}$ induced by $\mathrm{PHA}-\mathrm{P}$ at lower concentrations $\left(10^{-7}-10^{-6} \mathrm{~g} / \mathrm{ml}\right)$ and reduced the index at higher concentrations $\left(10^{-5}-10^{-4} \mathrm{~g} / \mathrm{ml}\right)$, and it caused a concentration-dependent reduction of $\mathrm{SI}$ induced by LPS. S. doederleinii at the highest concentration $\left(10^{-4} \mathrm{~g} / \mathrm{ml}\right)$ showed a tendency to reduce SI by PHA-P and reduced $\mathrm{SI}$ by LPS. A. macrocephala increased both Sis with PHA-P and, particularly, with LPS. S. subprostrata reduced both SIs by $\mathrm{PHA}-\mathrm{P}$ and LPS at the highest concentration $\left(10^{-4}\right.$ $\mathrm{g} / \mathrm{ml}$ ). None of these Chinese herbs affected the DNA amount of cells incubated without mitogens.

\section{Discussion}

There have been many reports $(1-3,9-$ 13) about the immunological response against Meth $A$ tumor in the syngeneic host, BALB/c mice. North and Bursuker (9) reported that the cells having the $L y-1-2^{+}$ phenotype of cytotoxic $T$ cells in mice play an important role in the concomitant immunity, showing tumor resistance. Others $(10,11,14)$ described the importance of the cells having the $L y-1^{+} 2^{-}$phenotype of helper/delayed hypersensitivity $T$ cells in mice. Previously, we (5) showed that Meth A tumor specific delayed type hypersensitivity induced in BALB/C mice after the primary tumor inoculation was detectable until 15 days, but decayed drastically by day 20 in inverse proportion to the tumor growth. Similarly, the neutralizing activity in the 
control was detected on days 10 and 15 after tumor transplantation, then decreased on day 20 to a level lower than that of normal spleen (Fig. 1). The mechanisms for the decay of the immunity seen on day 20 after the Meth A-inoculation have not been clear, although North (12) and DiGiacomo and North (13) reported the induction of suppressor $T$ cells which down-regulated effector $T$ cells in concomitant tumor immunity. The administration of $S$. doederleinii. A. macrocephala and $S$. subprostrata enhanced the tumor neutralizing activity in the spleen on day 10 or 15, and it prevented the decrease of the activity on day 20. A. capillaris did not affect the activity. It was, therefore, reconfirmed that these herbs except for $A$. capillaris could augment the immune response to resist the tumor growth. However, the precise mechanisms of the enhancing activity of these Chinese herbs on the tumor immune response are still unclear. Moreover, there is still much debate about whether delayed type hypersensitivity effector $T$ cells $(10,11,14$, $15)$ or cytotoxic $T$ cells $(9,12,13,15)$, or perhaps even both of them play a more important role in the host defense mechanisms against tumors. There are possibilities that all these $T$ cell subsets as well as activated macrophages $(3,10)$ contribute to the tumor-neutralizing activity found in this study.

We also examined the effect of the 4 kinds of Chinese herbs on immune responses other than tumor immune response to clarify their immunopharmacological profiles.

It has been established that the local GVHR is mediated primarily by the Lyt $-1^{-} 2^{+}$ phenotype of cytotoxic $T$ cells recognizing the major histocompatibility antigens. Markwick et al. (16) reported that not only graft lymphocytes but also recipient lymphocytes participate in the local GVHR. None of the Chinese herbs enhanced the GvHR, suggesting that these herbs do not affect this kind of cytotoxic T cell.

These Chinese herbs did not affect the spleen weight, differing from what was observed in the case of OK-432. Such a result indicates that these herbs have less side effects on immunological organs. $A$. capillaris hardly affected the humoral antibody formation to SRBC. On the contrary, the other 3 herbs including $S$. doederleinii, $A$. macrocephala and $S$. subprostrata enhanced the humoral antibody formation, especially $\lg M$ and $\lg G$ antibodies on day 10 .

Mitogen-induced lymphocyte proliferation in vitro is thought to be a model for the lymphocyte proliferation occurring in the immunological responses in vivo. It is wellknown that PHA-P stimulates $T$ cells and LPS stimulates $B$ cells of murine lymphocytes to cause them to transform and proliferate. A. capillaris suppressed the lymphocyte proliferation with PHA-P and LPS even at the relatively low concentration of $10^{-5} \mathrm{~g} / \mathrm{ml}$. Previously. we reported that this herb inhibited the tumor proliferation in vitro, and also this herb suppressed the subcutaneous growth of Meth A tumors in BALB/c-nu/nu mice. From the previous findings and the present result that $A$. capillaris showed no effect on the tumor-neutralizing activity, it is thought that $A$. capillaris exhibits the antitumor activity through a direct cytocidal action against the tumor. A suppressive effect of $A$. capillaris on the mitogen-induced lymphocyte proliferation might be a reflection of this cytocidal action. Here, it should be noticed that $A$. capillaris did not show any immunosuppressive action to GvHR and humoral antibody formation as was generally seen by carcinostatic agents such as 5 fluorouracil and $\mathrm{CY}$. Also, A. capillaris did not affect the resting cells in vitro. $S$. doederleinii and $S$. subprostrata suppressed the responses with PHA-P and LPS only at the highest dose. The enhancing activity of A. macrocephala on the LPS-induced lymphocyte proliferation may be related to its stimulating activity on humoral antibody formation as well as its immunological antitumor activity. Further investigations on the latter 3 herbs will be required to clarify the relationship between their humoral immunitystimulating activity and their enhancing activity on concomitant tumor immunity, including the tumor-neutralizing activity of spleen cells and tumor-induced delayed type hypersensitivity.

Acknowledgment: We thank Tsumura, Inc. for the generous gifts of the Chinese herbs employed in this study. 


\section{References}

1 Berendt, M.J., North, R.J. and Kirstein, D.P.: The immunological basis of endotoxin-induced tumor regression: Requirement for T-cellmediated immunity. J. Exp. Med. 148, 15501559 (1978)

2 Berendt, M.J., North, R.J. and Kirstein, D.P.: The immunological basis of endotoxin-induced tumor regression: Requirement for a pre-existing state of concomitant anti-tumor immunity. J. Exp. Med. 148, 1560-1569 (1978)

3 Miyata, H., Himeno, K. and Nomoto, K.: Mechanisms of the potentiation of specific antitumor immunity by intratumor injection of Corynebacterium parvum. Cancer Res. 43, 4670-4675 (1983)

4 Xu, Q., Teshima, K., Choi, S.H., Mori, H., Koda, A. and Nishioka, I.: Antitumor activity of some kinds of crude drugs. J. Med. Pharm. Soc. WAKAN-YAKU 3, 31-36 (1986) (Abs. in English)

5 Mori, H., Xu, Q., Sakamoto, O., Uesugi, Y., Ono, Y., Koda, A. and Nishioka, I.: Immunological mechanisms of antitumor activity of some kinds of Chinese herbs: Meth A-induced delayed type hypersensitivity. Japan. J. Pharmacol. 48, 37-46 (1988)

6 Cunningham, A.J. and Szenberg, A.: Further improvement in the plaque technique for detecting single antibody-forming cells. Immunology, 14, 559-602 (1968)

7 Sakamoto, O., Xu, Q., Mori, H. and Koda, A.: Titration of anti-sheep red blood cell (SRBC) antibody in mouse serum by enzyme linked immunosorbent assay (ELISA). Japan. J. Pharmacol. 43, Supp. 116P (1987)

8 Kind, P.R.N. and King, E.I.: Estimation of plasma phosphatase by determination of hydrolyzed phenol with antipyrine. J. Clin. Pathol. 7, 322326 (1954)

9 North, R.J. and Bursuker, 1.: Generation and decay of the immune response to a progressive fibrosarcoma: I. Ly-1+2- suppressor T cells downregulate the generation of $L y-1-2^{+}$effector $T$ cells. J. Exp. Med. 159, 1295-1311 (1984)

10 Mitani, M., Matsumoto, T., Mori, K., Miake, S., Himeno, K. and Nomoto, K.: Rejection of syngeneic tumor cells by the interaction of Lyt-1+ T lymphocytes and macrophages. J. Clin. Lab. Immunol. 18, 97-101 (1985)

11 Mitani, M., Mori, K., Himeno, K., Matsumoto, T., Taniguchi, K. and Nomoto, K.: The role of cytostasis in antitumor immunity: Comparison between syngeneic and allogeneic systems. Cell. Immunol. 92, 22-30 (1985)

12 North, R.J.: Radiation-induced, immunologically mediated regression of an established tumor as an example of successful therapeutic immunomanipulation: Preferential elimination of suppressor $T$ cells allows sustained production of effector T cells. J. Exp. Med. 164, 1652-1666 (1986)

13 DiGiacomo, A. and North, R.J.: $T$ cell suppressors of antitumor immunity: The production of $L y-1-2^{+}$suppressors of delayed sensitivity precedes the production of suppressors of protective immunity. J. Exp. Med. 164, 11791192 (1986)

14 Yoshioka, T., Sato, S., Ogata, M., Sakamoto, K., Sano, H., Shima, J. Yamamoto, H., Fujiwara, H. and Hamaoka, T.: Mediation of in vitro tumorneutralizing activity by $\mathrm{Ly}-2^{+}$as well as L3T4* $\mathrm{T}$ cell subsets. Japan. J. Cancer Res. (Gann) 79, 91-98 (1988)

15 Knisely, T.L., Luckenbach, M.W., Fischer, B.J. and Niederkorn, J.Y.: Destructive and nondestructive patterns of immuns rejection of syngeneic intraocular tumors. J. Immunol. 138, 4515-4523 (1987)

16 Markwick, J.R., Barnes, R.M.R. and Pegrum, G.D.: Allogeneic cell interactions in the rat: I. Changes in the rate of cell proliferation during local graft-versus-host and host-versus-graft reactions. Cell. Immunol. 32, 52-59 (1977) 